\section{Standing in line}

Graham Ritchie

From Carnac to Callanish: The Prehistoric Stone Rows and Avenues of Britain, Ireland and Brittany. By Aubrey Burl. Yale University Press: 1993. Pp. 286. £25, $\$ 45$.

THE standing stones of Britain, Ireland and Brittany capture the imagination of those who live daily in their shadow as well as those who chance upon them as tourists and travellers. The folklore associated with stones is as varied for single monoliths as it is for stone circles and linear arrangements. Circles and rows have a greater potential for drama than do the single uprights, epitomized by the legend of the Breton wedding party that refused to let a priest pass and was punished by petrification. One stone on the island of Jura has been likened to Queen Victoria in repose, and no-one looking at plate 15 of Long Meg and her Daughters near Penrith in Aubrey Burl's handsome volume can doubt that stones can become anthropomorphized very readily. It all depends on imagination.

Burl's The Stone Circles of the British Isles (Yale University Press, 1976) has rightly become a classic of archaeological presentation, outlining different types of monument and making an assessment of their dating evidence and social context. In the intervening years he has continued the study and has not avoided discussion of such controversial issues as complex geometrical shapes and the potential significance of astronomical alignments in the positioning of sites within their landscape. The present volume takes a more disparate group of monuments, linear settings of upright stones, stones in rows and avenues, and creates order where none had existed before. Much archaeological writing depends on giving the reader information about a group of individual monuments, location, earlier records of excavation and the surviving evidence, and then drawing the threads together in an interesting way; Burl is particularly skilful at doing this, incorporating engaging writing with unexpected allusions, thus maintaining the reader's interest throughout. Many of Burl's own fine photographs illustrate the book and help to evoke further the topographical setting of these monuments. Dating evidence is sparse, for it is rare that the hole in which a monolith has been set up has been excavated to modern standards and even rarer that useful dating evidence

has been discovered. In some cases a burial deposit has been found set into the stone-hole, but in most cases excavations around such sites have provided only the broadest indications of age. Thus Burl's classification makes the best use of a comparatively small amount of evidence and relies primarily on the number and arrangement of the stones in individual settings.

Burl believes that long stone rows developed from the avenues that led to stone

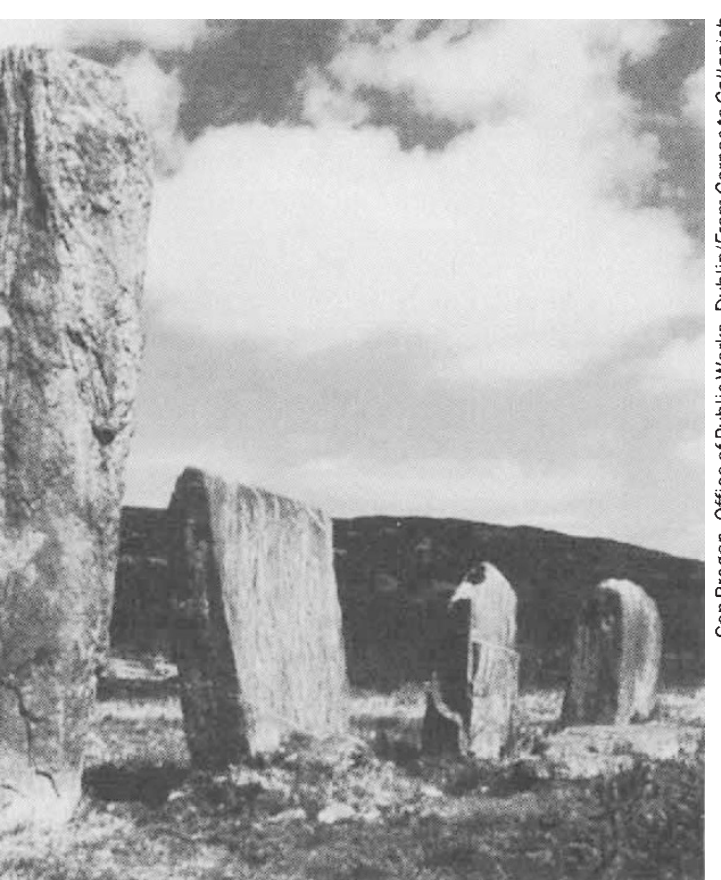

ones in Co. Cork, possibly aligned on the southern moonset. circles such as those at Avebury and Callanish, and he lists other less wellknown examples. The archaeology of such monuments is fully discussed, with both the possibilities and the problems fairly stated. The type of social structure capable of planning and accomplishing such engineering feats is evoked both by the surviving artefacts and by an assessment of the man-hours that might have been difficult to make, but a modern parallel involved 170 people pulling a 31 -ton block at no more than 100 yards a day. Stone rows not associated with any circle are a particular feature of Exmoor and Dartmoor, although a recent resurvey on Learable Hill in Sutherland confirms this as a northern outlier. Burl's photographs give a good impression of the scale of the rows in terms of their length within the landrequired. Such estimates are notoriously

scape, and the experience of survey, even with present-day equipment, underlines respect for the conceptual and constructional skills involved.

Rows of stones have not before been subjected to rigorous classification, and Burl's study is of particular value in drawing together a range of material from Ireland, Britain and Brittany and organizing it into a number of distinct categories: single rows of stones, multiple rows of stones, sometimes parallel sometimes in fan-like settings, and shorter rows in recognizable groups of between four and six, three, and pairs of stones. Although regional studies of such sites have been available in the past, Burl's volume is the first to place such sites into a broader context. Although the multiple rows capture the imagination of visitors to Brittany, both because of their vastness of scale in linear terms and because of the size of the stones, the fan-shaped settings of northern Scotland are equally complex in layout. Burl rightly draws attention to the importance of preserving the sites and aspects of their topographical setting for future research.

Shorter linear settings have puzzled archaeologists for generations; they are difficult to describe in such a way as to make a satisfactory evocation of the monument as an impressive statement in a prehistoric landscape. Yet they are major monuments of antiquity. Burl's impressive photographs do full justice both to the enigma of the stones themselves and to the topography in which they stand, perhaps as the foci for funerary or social rituals. Dance has always seemed a likely part of rituals using formalized layouts of stones, but it is impossible to document

\section{archaeologically.}

The apparatus of notes, county concordance and gazetteers is comprehensive, but quite difficult to use: Welsh counties are in their modern form, whereas Scotland is in its pre-1975 counties, but with the islands of Argyll scattered alphabetically. The constant user of the volume will come to grips with the mass of information; the more general reader will have no need of such background material and will be delighted by a lucid and well presented account of a comparatively unexplored aspect of prehistory.

Graham Ritchie is Depute Curator of the National Monuments Record of Scotland, part of the Royal Commission on the Ancient and Historical Monuments of Scotland, John Sinclair House, 16 Bernard Terrace, Edinburgh EH8 9NX, UK. 